\title{
The Neuropeptide Y Y5 Receptor Mediates the Blockade of "Photic-Like" NMDA-Induced Phase Shifts in the Golden Hamster
}

\author{
Paola C. Yannielli and Mary E. Harrington \\ Department of Psychology and Neuroscience Program, Smith College, Northampton, Massachusetts 01063
}

Circadian or daily rhythms generated from the mammalian suprachiasmatic nuclei (SCN) of the hypothalamus can be synchronized by light and nonphotic stimuli. Whereas glutamate mediates photic information, nonphotic information can in some cases be mediated by neuropeptide Y (NPY) or serotonin. NPY or serotonin can reduce the phase-resetting effect of light or glutamate; however, the mechanisms and level of interaction of these two kinds of stimuli are unknown. Here we investigate the effect of NPY on the NMDA-induced phase shift of the hamster SCN circadian neural activity rhythm by means of single-unit recording techniques.

NMDA (10-100 $\mu \mathrm{M})$ applied in the early subjective night induced phase delays in the time of peak firing, whereas doses in the millimolar range disrupted firing patterns. The NMDAinduced phase delay was blocked by coapplication of NPY
(0.02-200 $\mu \mathrm{M})$. NPY Y1/Y5 and Y5 receptor agonists, but not the $Y 2$ receptor agonist, blocked the NMDA-induced phase delay in a similar manner as NPY. The coapplication of a Y5 but not Y1 receptor antagonist eliminated NPY blockade of NMDAinduced phase delays, suggesting that the $Y 5$ receptor is capable of mediating the inhibitory effect of NPY on photic responses. These results indicate that nonphotic and photic stimuli may interact at a level at or beyond NMDA receptor response and indicate that the $\mathrm{Y} 5$ receptor is involved in this interaction. Alteration of $\mathrm{Y} 5$ receptor function may therefore be expected to alter synchronization of circadian rhythms to light.

Key words: circadian rhythms; Syrian hamster; NPY; NMDA; entrainment; photic-nonphotic interaction; single-unit activity; suprachiasmatic nuclei
Circadian or daily rhythms can be synchronized to $24 \mathrm{hr}$ cycles of the external environment through photic entrainment. Light has access to the hypothalamic suprachiasmatic nuclei (SCN), which functions as an endogenous circadian pacemaker in mammals, through a direct projection from retinal ganglion cells (Ebling, 1996). Light resets circadian rhythm phase during the subjective night. The daily oscillation in the firing rate of SCN neurons that can be observed for several $\sim 24 \mathrm{hr}$ cycles in vitro (Gillette, 1991) provides a unique system in which to examine the effect of resetting stimuli on the circadian clock. Glutamate can reset the phase of circadian rhythms in spontaneous firing rate in the SCN in vitro in a manner similar to light (Ding et al., 1994; Shibata et al., 1994; Biello et al., 1997). Both in vivo and in vitro studies suggest that NMDA as well as non-NMDA receptors are involved in mediation of the effect of light on the pacemaker (Colwell and Menaker, 1992; Ding et al., 1994; Shibata et al., 1994).

A variety of modulatory pathways allow flexibility in the animal's response to light. The thalamic intergeniculate leaflet projection to the SCN uses neuropeptide Y (NPY) (Harrington, 1997). NPY is able to reduce light-induced phase shifts, and SCN application of antiserum to NPY enhances photic phase shifts (Biello, 1995; Weber and Rea, 1997). This effect can be measured in vitro using glutamate or light (Biello et al., 1997; Yannielli and

Received Jan. 22, 2001; revised May 3, 2001; accepted May 3, 2001.

This work was supported by National Institutes of Health Grant NS26496 (M.E.H.). The technical assistance of Kimberly Wong, Carolyn Delk, and Jennifer Morgan is gratefully acknowledged. We gratefully acknowledge the gift of the two Y5 agonists used in this study from Dr. A. Beck-Sickinger, (Institute of Biochemistry, University of Leipzig, Leipzig, Germany) and the gift of the Y5 antagonist from the RW Johnson Pharmaceutical Research Institute (Spring House, PA).

Correspondence should be addressed to Mary E. Harrington, Neuroscience Program, Department of Psychology, Smith College, Northampton, MA 01063. E-mail: mharring@smith.edu.

Copyright @ $\odot 2001$ Society for Neuroscience 0270-6474/01/215367-07\$15.00/0
Harrington, 2000). However, in vivo experiments showed that microinjection of NPY into the hamster SCN after a light pulse decreased the magnitude of the phase advances, without affecting phase delays (Weber and Rea, 1997). Also, in vitro experiments showed that, in rats, coapplication of NPY at either circadian time (CT) 14 or CT 19 actually potentiated the phase-shifting effect of NMDA (Shibata et al., 1994).

The subtype of NPY receptor underlying NPY modulation of photic responses has not yet been investigated. The Y1 and Y5 receptors are expressed in rat SCN (Weinberg et al., 1996; Larsen and Kristensen, 1998), whereas the Y2 receptor appears to mediate the NPY phase-resetting action during the subjective day (Golombek et al., 1996; Huhman et al., 1996). The blocking effect of NPY on pituitary adenylate cyclase activating peptide-induced daytime phase shifts is via the Y1 and/or Y5 receptors (Harrington and Hoque, 1997), whereas in rats, the inhibitory effect of NPY on serotonergic phase is mediated by Y2 receptors (Prosser, 1998). Y1, Y2, and Y5 receptors have been implicated in the inhibitory effects of NPY on spontaneous discharge (Liou and Albers, 1991; van den Pol et al., 1996; Cutler at al., 1998; Gribkoff et al., 1998), as well as the NPY-induced long-term depression of glutamate-elicited EPSPs (van den Pol et al., 1996). A selective agonist as well as antagonist for the NPY Y5 receptor has just been reported (Cabrele et al., 2000; Youngman et al., 2000).

We report that NPY is able to block NMDA-induced phase shifts in vitro. We further report that the receptor mediating this effect is the Y5 receptor, the same receptor implicated in effects of NPY on food intake (Gerald et al., 1996; Hu et al., 1996) and seizure activity (Marsh et al., 1999).

\section{MATERIALS AND METHODS}

Animals and tissue preparation. Male golden hamsters (LVG; 40- to 60-d-old; Charles River Laboratories, Wilmington, MA) were housed 
with a 14/10 hr light/dark schedule (lights on at 5:00 A.M.), with food and water available ad libitum. Zeitgeber time (ZT) was defined as ZT 12 being the projected time of lights off in the animal room. Hamsters were administered an overdose of halothane anesthesia and decapitated during the subjective day, in most cases between ZT 8 and ZT 10. Hypothalamic slices $(500 \mu \mathrm{m})$ containing the SCN were placed in a gas-fluid interface slice chamber (Medical Systems brain slice chamber with Haas top), continuously bathed ( $1 \mathrm{ml} / \mathrm{min})$ in artificial CSF (ACSF) containing (in mM): $125.2 \mathrm{NaCl}, 3.8 \mathrm{KCl}, 1.2 \mathrm{KH}_{2} \mathrm{PO}_{4}, 1.8 \mathrm{CaCl}_{2}, 1 \mathrm{MgSO}_{4}, 24.8$ $\mathrm{NaHCO}_{3}$, and 10 glucose. ACSF, pH 7.4, was supplemented with an antibiotic $(50 \mathrm{mg} / \mathrm{l}$ gentamicin $)$ and a fungicide $(2 \mathrm{mg} / 1 \mathrm{amphotericin})$ and maintained at $34.5^{\circ} \mathrm{C}$. Warm, humidified $95 \%$ oxygen $-5 \%$ carbon dioxide was continuously provided.

Electrophysiological recordings. Extracellular single-unit activity of SCN cells was detected with glass micropipette electrodes filled with ACSF, advanced through the slice using a hydraulic microdrive. Every spontaneously firing cell with a signal distinguishable from noise was recorded. The signal was fed into an amplifier for additional amplification and filtering and was continuously monitored by an oscilloscope and audio monitor. Firing rate was analyzed using data acquisition software and a customized program for calculation of descriptive statistics. A number of experiments in each condition were recorded "blind" in which the person recording data had no knowledge of the contents of the microdrop. In the majority of the cases, only one slice was recorded from each animal, but when a second slice containing SCN was recordable, the treatment applied was different from that applied to the first slice of the same animal. A total number of 118 slices were recorded in the present study.

Drugs and treatments. Drugs were applied as a $200 \mathrm{nl}$ microdrop delivered to the SCN area of the slice at least $4 \mathrm{hr}$ after dissection, on the same day as slice preparation. When two drops were applied, there was an average of $5 \mathrm{~min}$ between drops. Recordings were performed for 6-8 hr. All of the drugs were applied at ZT 14 the same day the slices were prepared. The recordings started the following day, $2-3 \mathrm{hr}$ before $\mathrm{ZT} 30$ (the projected ZT 6 of the second day in vitro) and lasted until the firing rate returned to prepeak levels in all cases. The number of slices per treatment $(n)$ is stated in the corresponding figure or is mentioned in the text.

NMDA (Research Biochemicals, Natick, MA) diluted in fresh ACSF was applied in concentrations ranging from $1 \mu \mathrm{M}$ to $10 \mathrm{mM}$. Neuropeptide $\mathrm{Y}$ (rat and human; Bachem Bioscience, Torrance, CA) prepared in ACSF was applied as $0.002-200 \mathrm{ng}$ in $200 \mathrm{nl}(2.34 \mathrm{nM}-234 \mu \mathrm{M})$. The molecular weight of all of the agonists is very close to that of NPY, so that the higher concentration applied ( $200 \mathrm{ng} / 200 \mathrm{nl})$ was between 235 and $240 \mu \mathrm{M}$ for all receptor-specific agonists. Both Y5 agonists, bU8 ([hPP1-17, Ala ${ }^{31}$, $\left.\mathrm{Aib}^{32}\right] \mathrm{NPY}$ ) and bV5 ([Ala $\left.\left.{ }^{31}, \mathrm{Aib}^{32}\right] \mathrm{NPY}\right)$ (Cabrele et al., 2000), were generously provided by Dr. A Beck Sickinger (University of Leipzig, Leipzig, Germany). Y1/Y5 and Y2 agonists, $\left[\mathrm{Leu}^{31}{ }^{31} \mathrm{Pro}^{34}\right] \mathrm{NPY}$ and NPY3-36 respectively, were purchased from Sigma (St. Louis, MO). All of the NPY receptor agonists were applied the same way as NPY. The Y5 antagonist was generously provided by Dr. S. Dax (RW Johnson Pharmaceutical Research Institute, Spring House, PA). The Y5 antagonist RWJ57926 [ $\alpha$-(3-pyridylmethyl)- $\beta$-aminotetralin-derived sulfonamide] and the Y1 antagonist BIBP 3226 (R-N2-(diphenylacetyl)- $N$-(4-hydroxyphenyl)methyl-argininamide; Research Biochemicals) were prepared in ACSF (2 and $1 \mu \mathrm{M}$ final concentration, respectively), and applied in the bath from ZT 13.5 to ZT 14.5, alone or in combination with other treatments applied at ZT 14 as microdrops.

Data analysis. Data were initially grouped into $1 \mathrm{hr}$ bins, and an ANOVA was used to determine whether any bins differed from the others. If the ANOVA indicated significant differences, data were smoothed using $1 \mathrm{hr}$ running means with a $15 \mathrm{~min}$ lag. The zeitgeber time of the middle of the $1 \mathrm{hr}$ bin with the highest mean firing rate after processing by this smoother was taken as the time of peak firing rate for that slice. Phase shifts of individual slices were measured relative to the average time of peak firing of control slices. Significant differences between groups $(p<0.05)$ were determined by ANOVA followed by Dunnett's (for all vs control comparison) or StudentNewman-Keuls (for all pairwise comparison) methods when multiple comparison procedures were required. Means are reported $\pm \mathrm{SE}$.

\section{RESULTS}

\section{NMDA dose-response curve}

NMDA applied at ZT 14 induced a phase delay of the firing rate activity rhythm in a dose-dependent manner (Fig. $1 A$ ). The time of peak of control slices (ACSF microdrop at ZT 14), measured
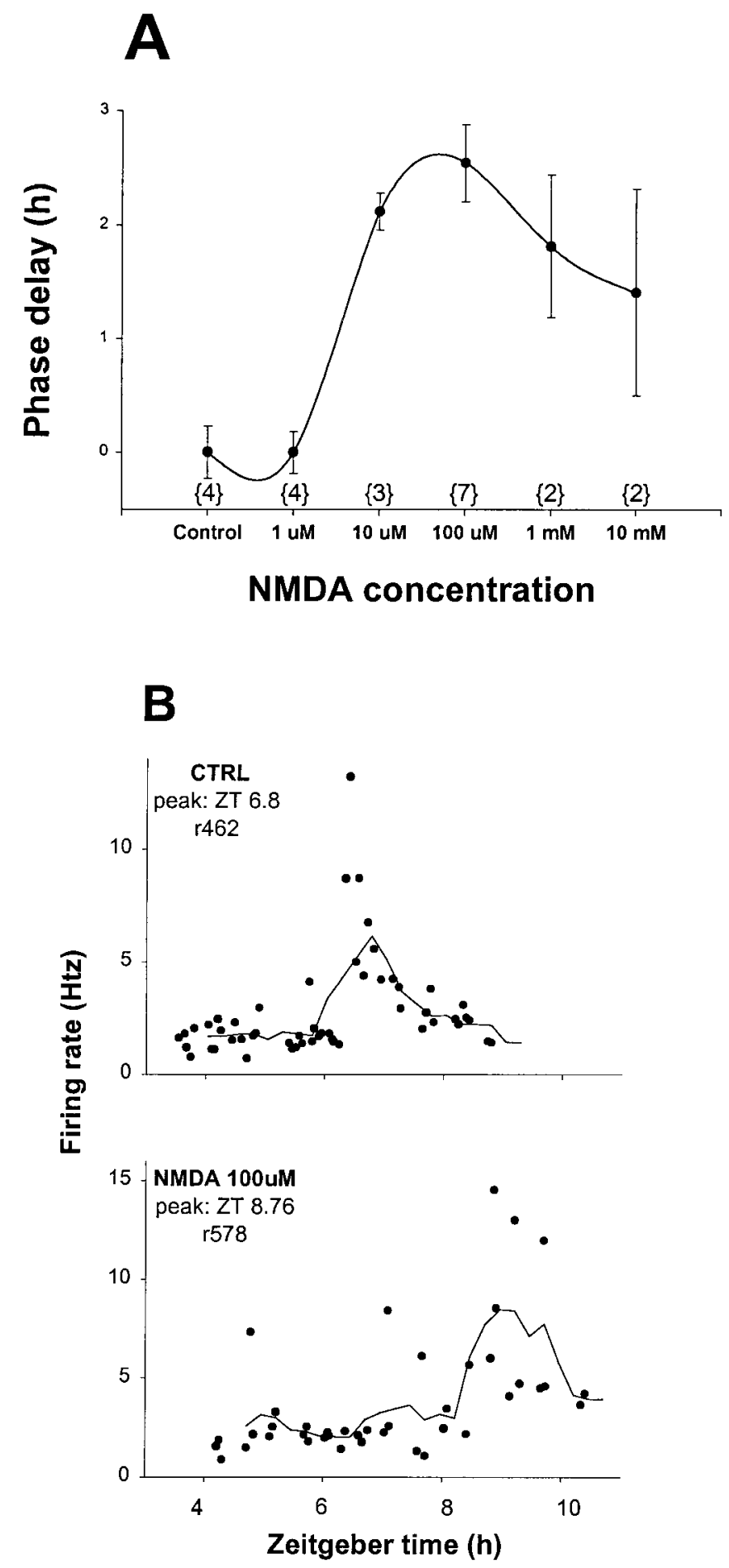

Figure 1. Dose-response curve for the phase-delaying effect of NMDA applied at ZT 14 on the first day in vitro. The rhythm of spontaneous firing rate was measured from SCN slices on the second day in vitro, and phase was measured relative to untreated control slices. $A$, Shown are the means \pm SE of phase delays (in hours) induced by administration of $1 \mu \mathrm{M}$ to $10 \mathrm{~mm}$ NMDA. The drug was applied in a volume of $200 \mathrm{nl}$ as a microdrop onto the SCN region. Average time of peak of control slices (ZT $6.36 \pm 0.23 \mathrm{hr}$ ) was used to define the phase shift. Number of slices are shown in brackets. The phase-shifting effect of NMDA was dose dependent, with all the treatments except $1 \mu \mathrm{M}$ significantly different from control values ( $p<0.05$; ANOVA followed by Dunnett's method). $B$, Representative individual recordings. Firing rate (in Hertz) of individual SCN neurons plotted against zeitgeber time of recording during the second day in vitro. Solid line indicates the running mean smoother. 


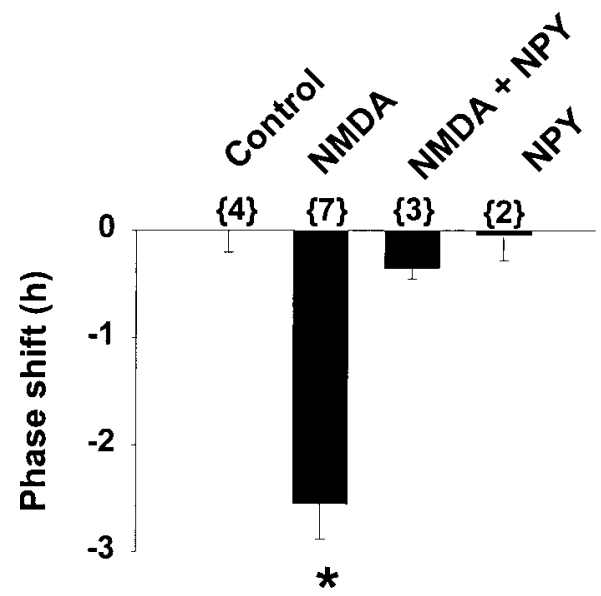

Figure 2. Effect of NPY on NMDA-induced phase delays. NPY significantly blocked NMDA-induced phase delays, whereas NPY alone did not modify the phase of the firing activity rhythm $\left({ }^{*} p<0.05\right.$; NMDA alone vs NMDA plus NPY; ANOVA followed by Student-Newman-Keuls method). Shown are the means \pm SE of phase delays (expressed as hours, in negative values) induced by $100 \mu \mathrm{M}$ NMDA applied alone or followed by $200 \mathrm{ng}$ of NPY $(234 \mu \mathrm{M})$. Both drugs were applied in a volume of 200 $\mathrm{nl}$ as microdrops onto the SCN region. Control values are shown for comparison purposes, as well as $200 \mathrm{ng}$ of NPY applied alone. Number of treated slices is denoted in brackets.

on the second day in vitro, was in the middle of the subjective day (average ZT, $6.36 \pm 0.23 \mathrm{hr}$ ) as reported previously. NMDA induced a significant phase delay at concentrations of 10 and 100 $\mu \mathrm{M}(2.12 \pm 0.16$ and $2.55 \pm 0.3 \mathrm{hr}$, respectively), whereas concentrations of and above the millimolar range (1 and $10 \mathrm{~mm})$ induced a disrupted rhythm pattern, expressed as double peaks and/or overall diminished firing rate activity. It should be noted that, although three to four slices were treated with 1 or $10 \mathrm{~mm}$ NMDA, only two of them in each treatment could be included in the analysis, because the peak was not significant in the ANOVA of the other recordings. Saturation of the phase-shifting response to NMDA was achieved at $100 \mu \mathrm{M}$, which was then chosen as a working concentration for all of the following experiments, unless otherwise noted. Representative individual recordings from control and NMDA $(100 \mu \mathrm{M})$-treated slices are shown in Figure $1 B$.

\section{Effect of NPY on NMDA-induced phase delays}

As shown in Figure 2, application of $200 \mathrm{ng} / 200 \mathrm{nl}$ NPY $(234 \mu \mathrm{M})$ 5 min after NMDA $(100 \mu \mathrm{M})$ at ZT 14 completely blocked the phase-delaying effect of NMDA (NMDA average phase shift, $-2.55 \pm 0.3 \mathrm{hr}$; NMDA plus NPY average phase shift, $-0.35 \pm$ $0.1 \mathrm{hr}$ ). No significant changes in phase were found after the same concentration of NPY was applied alone $(-0.04 \pm 0.2 \mathrm{hr})$. Both of the clearly phase-shifting concentrations of NMDA (10 and $100 \mu \mathrm{M})$ were blocked by NPY application (10 $\mu \mathrm{M}$ NMDA plus $200 \mathrm{ng} / 200 \mathrm{nl}$ NPY average phase shift, $0.46 \pm 0.05 \mathrm{hr})$.

\section{Dose-response curves for NPY, Y1/Y5, Y2, and Y5 agonists}

Figure 3 shows the inhibitory effect of several concentrations of NPY on NMDA-induced phase delays, as well as the effect of the Y1/Y5 ([Leu ${ }^{31}$, Pro $\left.\left.^{34}\right] \mathrm{NPY}\right)$, Y5 [bU8 ([hPP1-17,Ala $\left.\left.{ }^{31}, \mathrm{Aib}^{32}\right] \mathrm{NPY}\right)$ and bV5 ([Ala $\left.\left.\left.{ }^{31}, \mathrm{Aib}^{32}\right] \mathrm{NPY}\right)\right]$ and Y2 (NPY3-36) agonists, applied in the same way as NPY. NPY blocked the effect of NMDA at concentrations of $0.02-200 \mu \mathrm{M}$, whereas at $2 \mathrm{nM}(0.002 \mathrm{ng} / 200 \mathrm{nl})$ the blocking effect was no longer evident. Furthermore, the Y1/Y5 and both Y5 agonists used in this experiment blocked the NMDA-

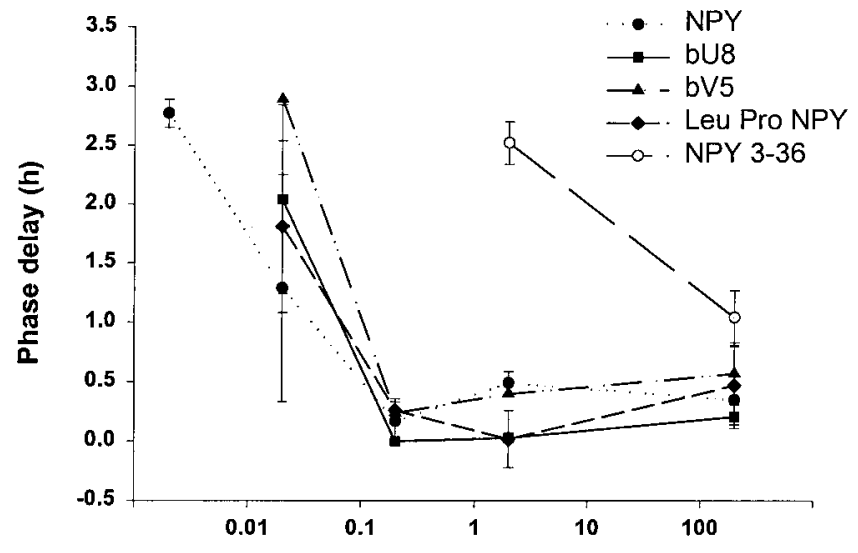

NMDA 100uM + NPY or agonist (ng/200nl)

Figure 3. Dose-response curves for NPY, Y1/Y5, Y2, and Y5 agonists blocking effect on NMDA-induced phase delay. Shown are the means \pm SE of phase delays expressed in hours. NMDA $(100 \mu \mathrm{M})$ was applied in all cases at ZT 14, 5 min before the NPY or agonists. The NPY blocking effect was significant at concentrations as low as $0.02 \mathrm{ng}(0.0234 \mu \mathrm{M})$, whereas the Y1/Y5 and both Y5 agonists blocked NMDA-induced phase delays at $0.2 \mathrm{ng}(0.235-0.238 \mu \mathrm{M})$. The $\mathrm{Y} 2$ agonist failed to block the NMDA phase-delaying effect at $2 \mathrm{ng}(2.4 \mu \mathrm{M})$. None of the agonists applied alone induced a phase shift of the firing activity rhythm (see Results). All drugs were applied in a volume of $200 \mathrm{nl}$, as microdrops onto the SCN region of the slices. Number of treated slices was two to four per group.

induced phase delay at concentrations as low as $0.2 \mu \mathrm{M}$, whereas the Y2 agonist failed to block the delays at $2 \mu \mathrm{M}$. No significant changes in the phase of the firing rate rhythm were found when the agonists were applied alone at ZT $14(0.05 \pm 0.01 \mathrm{hr}$ for Y1/Y5 agonist; 0.09 hr for Y2 agonist; -0.1 and -0.17 hr for the two Y5 agonists, bV5 and bU8, respectively). The Y1/Y5 and both Y5 agonists paralleled the effect of NPY even at very low concentrations, suggesting that the inhibition of photic-induced responses could be achieved through one or both of these receptors. Figure 4 shows representative recordings of $100 \mu \mathrm{M}$ NMDA, with or without different concentrations of NPY or Y5 agonist.

\section{Effect of Y5 and Y1 antagonists on NPY blockade of NMDA-induced phase shifts}

We decided to test the effect of the selective and potent Y5 antagonist RJW-57926 (McNally et al., 2000; Youngman et al., 2000) and the Y1 antagonist BIBP 3226 (Rudolf et al., 1994; Wieland et al., 1995), applied in the bath from ZT 13.5 to ZT 14.5. At ZT 14, NMDA (100 $\mu \mathrm{M})$, alone or in combination with NPY, was applied as described previously. Figure 5 shows that the blocking effect of NPY was not affected by $1 \mathrm{hr}$ administration of the Y1 antagonist (100 $\mu \mathrm{M}$ NMDA plus $2.34 \mu \mathrm{M}$ NPY plus $1 \mu \mathrm{M}$ Y1 antagonist, $0.32 \pm 0.13 \mathrm{hr} ; 100 \mu \mathrm{M}$ NMDA plus $2.34 \mu \mathrm{M} \mathrm{NPY}$, $0.49 \pm 0.1 \mathrm{hr}$ ) but was eliminated by coapplication of the Y5 antagonist $(100 \mu \mathrm{M}$ NMDA plus $2.34 \mu \mathrm{M}$ NPY plus $2 \mu \mathrm{M}$ Y5 antagonist, $3.00 \pm 0.15 \mathrm{hr} ; 100 \mu \mathrm{M}$ NMDA plus $2.34 \mu \mathrm{M}$ NPY, $0.49 \pm 0.1)$. No significant effect of either antagonist applied alone was found on control time of peak (Y1 antagonist, $0.37 \pm$ $0.18 \mathrm{hr}$; Y5 antagonist, $0.77 \pm 0.18$ ) or in NMDA-induced phase delays (NMDA plus Y1 antagonist, $2.23 \pm 0.35 \mathrm{hr}$; NMDA plus Y5 antagonist, $2.83 \pm 0.19)$ or NPY applied alone (2.34 $\mu \mathrm{M}$ NPY plus Y1 antagonist, $0.39 \mathrm{hr} ; 234 \mu \mathrm{M}$ NPY plus Y5 antagonist, 0.01 hr). Figure 6 shows representative individual recordings for the relevant treatments. 
Figure 4. The phase delay induced by NMDA (top left) is blocked by NPY at 0.02 ng (top right) and the Y5 agonist (bottom right) but not by NPY at $0.002 \mathrm{ng}$ (bottom left). The firing rate of individual neurons (dots) was plotted against the zeitgeber time of recording of the second day in vitro. Drugs were applied as stated in Materials and Methods. Peak times as indicated by the running mean smoother (line), and treatments are denoted in each graph showing a representative individual recording.
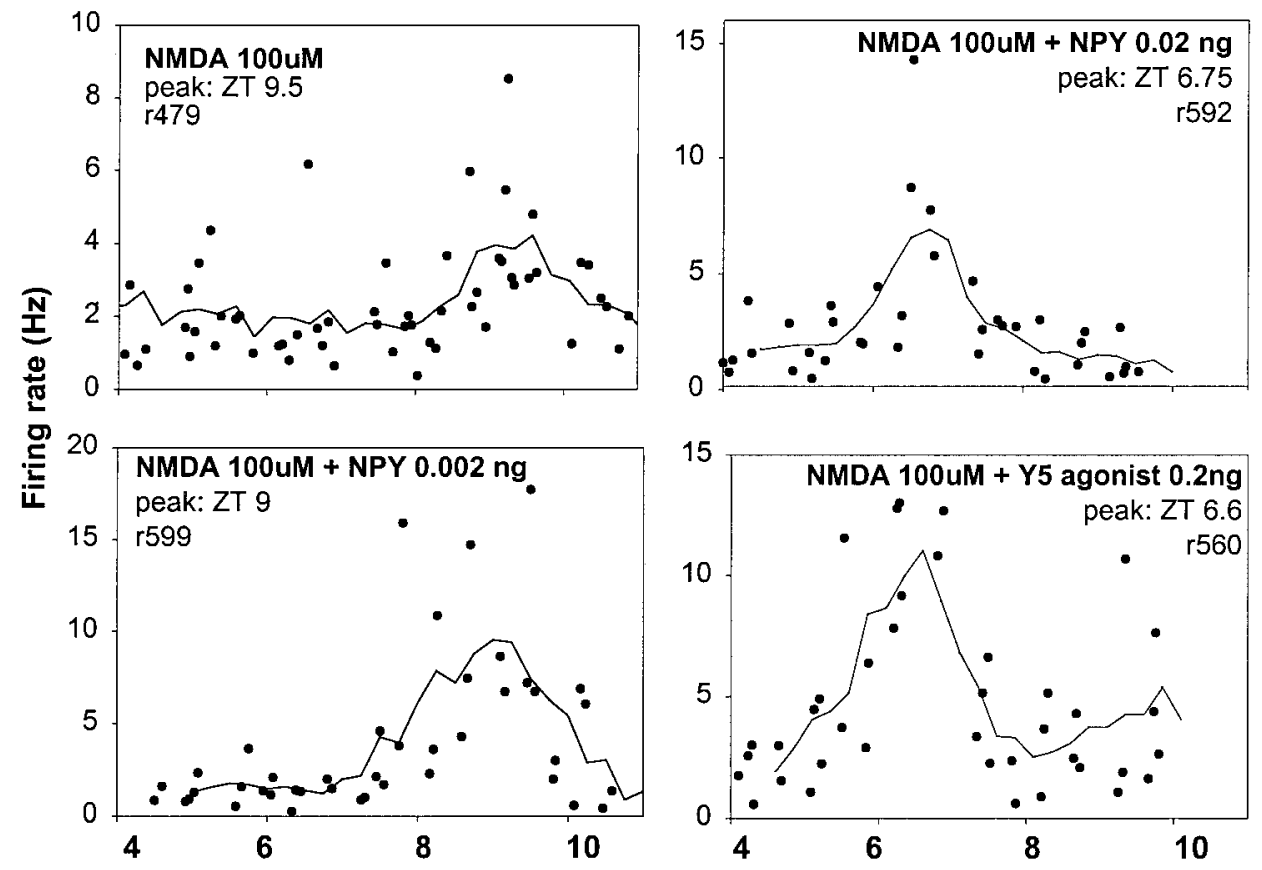

Zeitgeber time (h)

\section{DISCUSSION}

We have demonstrated that NPY can block photic phase shifts via the Y5 receptor and at some level at or beyond NMDA-receptor activation in the signal transduction cascade induced by light.

Initially, we characterized NMDA-induced phase shifts in the early subjective night (ZT 14) in the hamster SCN in vitro. NMDA induced a phase delay of $\sim 3 \mathrm{hr}$ when applied onto the $\mathrm{SCN}$ region. The phase-shifting effect was clearly dose dependent, with maximal phase-delay response at $100 \mu \mathrm{M}$ NMDA. The phase-shifting effects of NMDA have been shown to be similar to those of light, in that phase delays are elicited in early subjective night, phase advances later in the subjective night, with little phase shifting observed after treatment in the subjective day (Mintz et al., 1999). It appears that millimolar doses of NMDA are required for phase-shifting behavioral activity rhythms using in vivo microinjections of NMDA in hamsters (Mintz et al., 1999). Doses in the millimolar range in our study induced double peaks and decreased firing activity in half of the slices. A similar disrupted pattern was seen after glutamate applications to rat SCN slices at CT 14 (Shirakawa and Moore, 1994) and might be similar to responses reported for glutamate applications at ZT 17 in vitro (Ding et al., 1994; Franken et al., 1999).

We demonstrate that NPY blocks the phase-shifting effect of NMDA at ZT 14. This is similar to our previous results, in which NPY blocked the phase shifts induced by glutamate or light at ZT 14 and ZT 18 (Biello et al., 1997; Yannielli and Harrington, 2000). It is interesting that novel wheel access, a treatment that produces phase shifts dependent on NPY (Biello et al., 1994), was also able to block phase advances to light (Ralph and Mrosovsky, 1992). However, our results are in apparent conflict with several previously published studies. In rat SCN, coapplication of NPY potentiates both advance and delay shifts induced by NMDA in vitro (Shibata et al., 1994). It is unclear why this result is so different from ours, but it may be significant that these animals were housed under constant darkness for 24-48 hr before experimentation. In a behavioral study, NPY did not alter phase delays

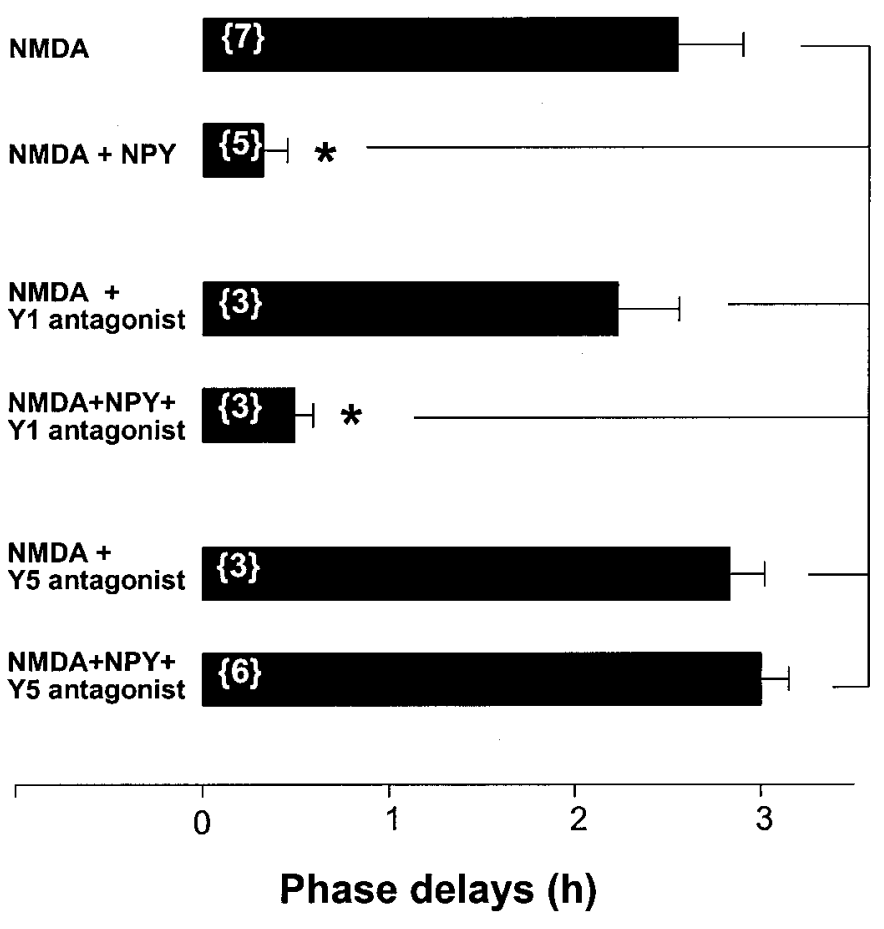

Figure 5. Effect of the Y5 and Y1 antagonists on NPY blockade of NMDA-induced phase delays. Shown are the means \pm SE of phase delays induced by NMDA $(100 \mu \mathrm{M})$ plus NPY $(2 \mathrm{ng})$, in the presence or absence of $1 \mathrm{hr}$ perfusion of Y1 antagonist BIBP $3226(1 \mu \mathrm{M})$ or Y5 antagonist RWJ $57926(2 \mu \mathrm{M})$. The Y5 antagonist significantly reversed the blockade of NPY on NMDA-induced phase delays, whereas the Y1 antagonist did not change the blocking effect of NPY on NMDA-induced phase delays. None of the antagonists interacted with the NMDA effect when applied alone, or NPY or control peak time values. Significant differences were as follows: NMDA alone, NMDA plus Y1 antagonist, NMDA plus Y5 antagonist, and NMDA plus NPY plus Y5 antagonist versus all the other treatments, including the Y1 and Y5 antagonists applied alone; * $p<0.05$; ANOVA followed by Student-Newman-Keuls method. 


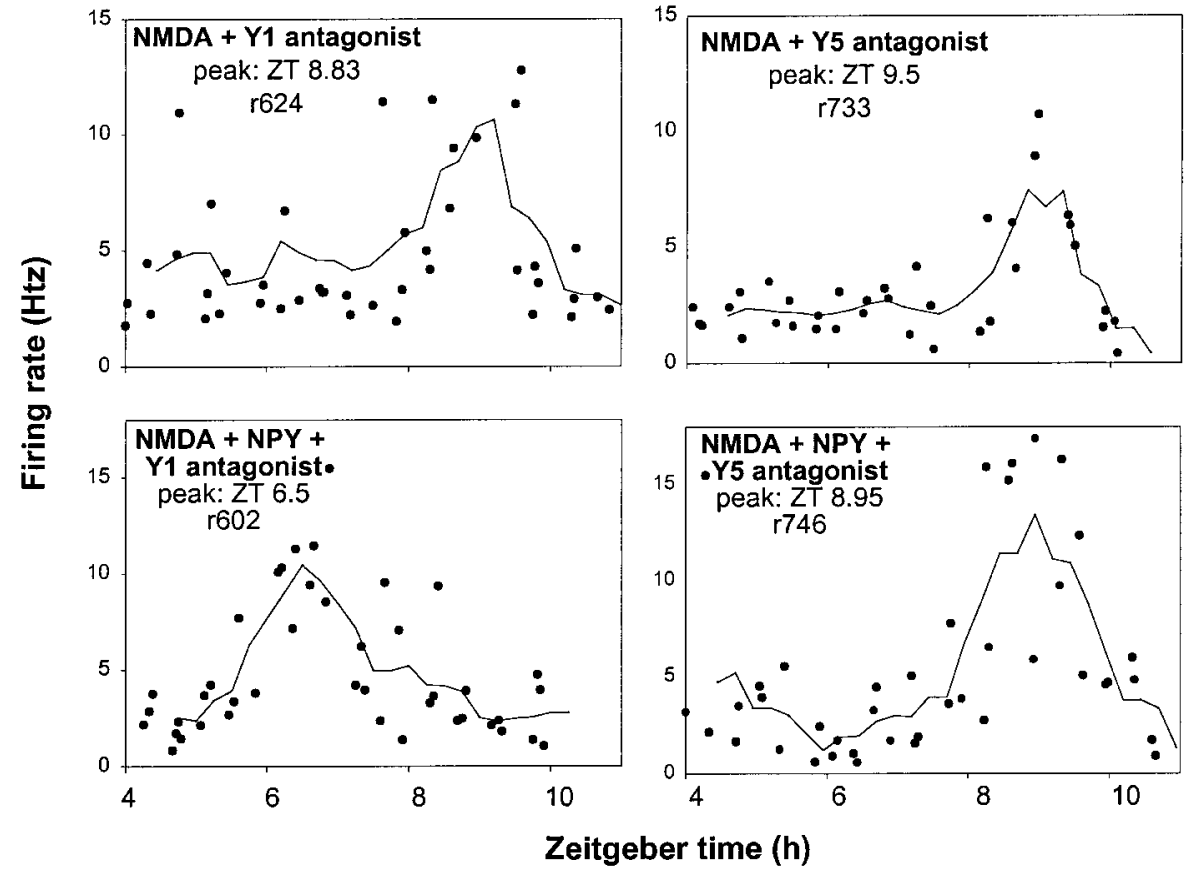

Figure 6. The NPY-induced block of the phase delay of NMDA is prevented by bath application of a Y5 antagonist (bottom right) but not by the Y1 antagonist (bottom left). Neither antagonist alone altered the phase delay induced by NMDA (top graphs). The firing rate of individual neurons (dots) was plotted against the zeitgeber time of recording of the second day in vitro. Drugs were applied as stated in Materials and Methods. Peak times as indicated by the running mean smoother (line), and treatments are denoted in each graph showing a representative individual recording. to light but did reduce light-induced phase advances (Weber and Rea, 1997).

There are at least six known subtypes of neuropeptide $\mathrm{Y}$ receptor (for review, see Ingenhoven and Beck-Sickinger, 1999). The Y2 receptor can be distinguished by its responsiveness to NPY3-36 (Grandt et al., 1996), whereas [Leu ${ }^{31}$,Pro $\left.{ }^{34}\right]$ NPY has often been used as a Y1 receptor agonist (Fuhlendorff et al., 1990), although it can also bind to the Y5 receptor (Ingenhoven and Beck-Sickinger, 1999). Two new compounds [bU8 ([hPP1-17, $\left.\left.\mathrm{Ala}^{31}, \mathrm{Aib}^{32}\right] \mathrm{NPY}\right)$ and bV5 ([Ala $\left.\left.\left.{ }^{31}, \mathrm{Aib}^{32}\right] \mathrm{NPY}\right)\right]$ bind to the Y5 receptor with higher affinity than other known NPY receptors (Cabrele et al., 2000). Also, a new Y5 receptor antagonist (RWJ 57926) has been developed recently and has been shown to bind selectively and potently to Y5 receptors in vitro, as well as to inhibit the ingestive behavior in rats (Youngman et al., 2000). Our work using these compounds indicates that the Y5 receptor mediates the blocking effect of NPY on NMDA-induced phase shifts. Thus, the receptor by which NPY can induce phase advances during the subjective day [the Y2 receptor (Golombek et al., 1996; Huhman et al., 1996)] is different from the receptor by which NPY presumably inhibits photic phase shifts during the subjective night. The rat SCN shows high levels of expression of the mRNAs encoding the Y1 and Y5 but not the Y2 or Y4 receptors (Larsen and Kristensen, 1998). The higher levels of expression of the Y5 versus the Y2 receptor in the SCN might explain the much lower concentrations of NPY needed to block NMDA-induced phase shifts $(\sim 0.02 \mu \mathrm{M})$ (Fig. 3) versus those necessary for NPY-induced phase shifts in the subjective day ( $20 \mu \mathrm{M})$ (Golombek et al., 1996).

Our results indicate that NPY acts at some point at or beyond NMDA receptor response in the light-induced signal transduction cascade. One possibility is that photic and nonphotic signals could interact via effects on membrane potential. In general, glutamate is depolarizing (Meijer et al., 1993), whereas NPY is hyperpolarizing (van den Pol et al., 1996; Hall et al., 1999). NPY can activate a $\mathrm{K}^{+}$-selective conductance in the $\mathrm{SCN}$, and although the subjective day phase-shifting action of NPY does not depend on the action of NPY to increase $\mathrm{K}^{+}$channel conductance (Hall et al., 1999), it remains possible that effects of NPY on light-induced shifts are mediated via these changes in $\mathrm{K}^{+}$conductance. Y5 agonists can induce inhibition of firing activity without affecting the phase of the activity rhythm (Harrington and Hoque, 1997; Cutler et al., 1998; Gribkoff et al., 1998). These data suggest that the phase-shifting effect of NPY and the inhibition of light-induced phase shifts by NPY could be mediated by different mechanisms. It is interesting that serotonin and melatonin also appear to use a different receptor subtype for their subjective day phase-shifting effects on circadian rhythms than the subtype mediating inhibitory effects on either photic responses or electrical activity (Rea et al., 1994; Liu et al., 1997; Pickard and Rea, 1998).

NPY may alter NMDA response by effects on intracellular calcium levels. NPY induces a long-term depression in glutamatestimulated rises in intracellular calcium levels (van den Pol et al., 1996). Both the Y1/Y5 and Y2 receptors were implicated in these effects, which were only seen concomitant with glutamatergic receptor activation. Serotonergic stimulation is associated with similar reductions in glutamate-induced calcium responses (Quintero and McMahon, 1999) and also with similar reductions of light-induced phase shifts (Rea et al., 1994; Pickard and Rea, 1998; Weber et al., 1998). Because activation of the Y5 receptor also leads to inhibition of cAMP accumulation (Gerald et al., 1996), cAMP reduction could be a possible mechanism of action. Recent results have shown that inhibitors of protein kinase A can block glutamate-induced phase shifts in vitro in rats (Tischkau et al., 2000), and in our laboratory, we have observed a similar result using hamsters (our unpublished results). This raises the possibility that NPY could inhibit cAMP accumulation and thus a step in the light-activated pathway.

NPY may ultimately work by changing gene expression; for example, altering levels of some recently identified circadian clock-related genes (for review, see Dunlap, 1999). NPY might suppress light-induced gene expression and thus might negatively modulate light input. Preliminary results of our laboratory show 
that NPY has an inhibitory effect on light-induced per1 and per2 in vitro (McKinley Brewer et al., 2000). During the subjective day, both NPY and novel wheel access [a stimulus associated with NPY (Biello et al., 1994; Janik and Mrosovsky, 1994)] can decrease mper1 and mper2 levels in hamster SCN (Maywood et al., 1999; Fukuhara et al., 2000; Maywood and Hastings, 2000). Because the phase-resetting action of NPY in the subjective day does not require de novo synthesis of clock proteins (Hall et al., 1999) and novel wheel access does not alter PER1 protein levels (Maywood et al., 1999), it is probable that the action of NPY on levels of per gene mRNA in the subjective day is more closely related to the action of NPY in the subjective night and does not play a causal role in the subjective daytime resetting action of NPY. This is supported by the lack of subjective day resetting when mPerl antisense was administered to the suprachiasmatic nucleus (Akiyama et al., 1999). In summary, the effect of NPY through its Y5 receptor during the subjective night could be attributable to many possible mechanisms, including inhibition of the increased electrical activity elicited by light-glutamateNMDA, inhibition of $\mathrm{Ca}^{2+}$ rise, and effects on clock gene expression.

Under either natural or seminatural conditions, nocturnal rodents, including hamsters, sample light during brief periods to entrain their internal cycle to the external $24 \mathrm{hr}$ cycle (DeCoursey, 1986; Pratt and Goldman, 1986). NPY appears to play a role in negatively modulating this fundamental response. NPY is seasonally regulated in some mammals (Ribelayga et al., 1998) and thus may alter circadian rhythm entrainment in a seasondependent manner. If verified in humans, the ability of NPY to modulate the circadian-clock responses to light may be of clinical importance. Pharmaceuticals that target NPY receptors are under development for use in humans as anti-obesity agents; these would be expected to also alter photic entrainment of circadian rhythms. It is important to note that the mechanism by which NPY blocks photic effects might be different from the mechanism by which NPY can phase shift the clock during the day. Additional studies should be directed toward understanding the underlying mechanism, as well as the functional relevance of these effects.

\section{REFERENCES}

Akiyama M, Kouzu Y, Takahashi S, Wakamatsu H, Moriya T, Maetani M, Watanabe S, Tei H, Sakaki Y, Shibata S (1999) Inhibition of lightor glutamate-induced mPer1 expression represses the phase shifts into the mouse circadian locomotor and suprachiasmatic firing rhythms. J Neurosci 19:1115-1121.

Biello SM (1995) Enhanced photic phase shifting after treatment with antiserum to neuropeptide Y. Brain Res 673:25-29.

Biello SM, Janik D, Mrosovsky N (1994) Neuropeptide Y and behaviorally induced phase shifts. Neuroscience 62:273-279.

Biello SM, Golombek D, Harrington ME (1997) Neuropeptide Y and glutamate block each other's phase shifts in the suprachiasmatic nucleus in vitro. Neuroscience 77:1049-1057.

Cabrele C, Langer M, Bader R, Wieland HA, Doods HN, Zerbe O, Beck-Sickinger AG (2000) The first selective agonist at the neuropeptide Y Y5-Receptor increases food intake in rats. J Biol Chem 275:36043-36048.

Colwell CS, Menaker M (1992) NMDA as well as non-NMDA receptor antagonists can prevent the phase-shifting effects of light on the circadian system of the golden hamster. J Biol Rhythms 7:125-136.

Cutler DJ, Piggins HD, Selbie LA, Mason R (1998) Responses to neuropeptide $\mathrm{Y}$ in adult hamster suprachiasmatic nucleus neurones in vitro. Eur J Pharmacol 345:155-162.

DeCoursey PJ (1986) Light-sampling behavior in photoentrainment of a rodent circadian rhythm. J Comp Physiol [A] 159:161-169.

Ding JM, Chen D, Weber ET, Faiman LE, Rea MA, Gillette MU (1994) Resetting the biological clock: mediation of nocturnal circadian shifts by glutamate and nitric oxide. Science 266:1713-1717.

Dunlap JC (1999) Molecular bases for circadian clocks. Cell 96:271-290.
Ebling FJ (1996) The role of glutamate in the photic regulation of the suprachiasmatic nucleus. Prog Neurobiol 50:109-132.

Franken P, Cao V, Heller HC, Miller JD (1999) The glutamate induced phase shift in the SCN slice: a two pulse study. Brain Res 818:34-40. Fuhlendorff J, Gether U, Aakerlund L, Langeland-Johansen N, Thogersen H, Melberg SG, Olsen UB, Thastrup O, Schwartz TW (1990) [Leu31, Pro34] neuropeptide Y: a specific Y1 receptor agonist. Proc Natl Acad Sci USA 87:182-186.

Fukuhara C, McKinley Brewer J, Bittman E, Harrington ME (2000) Effect of neuropeptide Y on PER1 gene expression in the hamster SCN in vitro. Soc Res Biol Rhythms Abstr 7:54.

Gerald C, Walker MW, Criscione L, Gustafson EL, Batzl-Hartmann C, Smith KE, Vaysse P, Durkin MM, Laz TM, Linemeyer DL, Schaffhauser AO, Whitebread S, Hofbauer KG, Taber RI, Branchek TA, Weinshank RL (1996) A receptor subtype involved in neuropeptideY-induced food intake. Nature 382:168-171.

Gillette MU (1991) SCN electrophysiology in vitro: rhythmic activity and endogenous clock properties. In: Suprachiasmatic nucleus: the mind's clock (Klein DC, Moore RY, Reppert SM, eds). New York: Oxford UP.

Golombek DA, Biello SM, Rendon RA, Harrington ME (1996) Neuropeptide phase shifts the circadian clock in vitro via a Y2 receptor. NeuroReport 7:1315-1319.

Grandt D, Schimiczek M, Rascher W, Feth F, Shively J, Lee TD, Davis MT, Reeve Jr JR, Michel MC (1996) Neuropeptide Y 3-36 is an endogenous ligand selective for Y2 receptors. Regul Pept 67:33-37.

Gribkoff VK, Pieschl RL, Wisialowski TA, van den Pol AN, Yocca FD (1998) Phase shifting of circadian rhythms and depression of neuronal activity in the rat suprachiasmatic nucleus by neuropeptide Y: mediation by different receptor subtypes. J Neurosci 18:3014-3022.

Hall AC, Earle-Cruickshanks G, Harrington ME (1999) Role of membrane conductances and protein synthesis in subjective day phase advances of the hamster circadian clock by neuropeptideY. Eur J Neurosci 11:3424-3432.

Harrington ME (1997) The ventral lateral geniculate nucleus and the intergeniculate leaflet: interrelated structures in the visual and circadian systems. Neurosci Biobehav Rev 21:705-727.

Harrington ME, Hoque S (1997) NPY opposes PACAP phase shifts via receptors different from those involved in NPY phase shifts. NeuroReport 8:2677-2680.

Hu Y, Bloomquist BT, Cornfield LJ, DeCarr LB, Flores-Riveros JR, Friedman L, Jiang P, Lewis-Higgins L, Sadlowski Y, Schaefer J, Velazquez N, McCaleb ML (1996) Identification of a novel hypothalamic neuropeptide Y receptor associated with feeding behavior. J Biol Chem 271:26315-26319.

Huhman KL, Gillespie CF, Marvel CL, Albers HE (1996) Neuropeptide $\mathrm{Y}$ phase shifts circadian rhythms via $\mathrm{Y}_{2}$-like receptors. NeuroReport 7:1249-1252.

Ingenhoven N, Beck-Sickinger AG (1999) Molecular characterization of the ligand-receptor interaction of neuropeptide Y. Curr Med Chem 6:1055-1066.

Janik D, Mrosovsky N (1994) Intergeniculate leaflet lesions and behaviorally-induced shifts of circadian rhythms. Brain Res 651:174-182.

Larsen PJ, Kristensen P (1998) Distribution of neuropeptide Y receptor expression in the rat suprachiasmatic nucleus. Brain Res Mol Brain Res 60:69-76.

Liou SY, Albers HE (1991) Single unit response of neurons within the hamster suprachiasmatic nucleus to neuropeptide $\mathrm{Y}$ in the hypothalamic slice preparation. Brain Res Bull 27:825-828.

Liu C, Weaver DR, Jin X, Shearman LP, Pieschl RL, Gribkoff VK, Reppert SM (1997) Molecular dissection of two distinct actions of melatonin on the suprachiasmatic circadian clock. Neuron 19:91-102.

Marsh DJ, Baraban SC, Hollopeter G, Palmiter RD (1999) Role of the Y5 neuropeptide Y receptor in limbic seizures. Proc Natl Acad Sci USA 96:13518-13523.

Maywood ES, Hastings MH (2000) The effect of central infusions of NPY on the expression of clock genes in the suprachiasmatic nuclei of the mouse. Soc Res Biol Rhythms Abstr 7:32.

Maywood ES, Mrosovsky N, Field MD, Hastings MH (1999) Rapid down-regulation of mammalian period genes during behavioral resetting of the circadian clock. Proc Natl Acad Sci USA 96:15211-15216.

McKinley Brewer J, Yannielli PC, Harrington ME (2000) Light exposure prior to slice preparation can induce increased PER1 and PER2 levels measured in vitro. Soc Res Biol Rhythms Abstr 7:53.

McNally JJ, Youngman MA, Lovenberg TW, Nepomuceno D, Wilson S, Dax S (2000) $N$-Acylated $\alpha$-(3-pyridylmethyl)- $\beta$-aminotetralin antagonists of the human neuropeptide Y Y5 receptor. Bioorg Med Chem Lett 10:1641-1643.

Meijer JH, Albus H, Weidema F, Ravesloot JH (1993) The effects of glutamate on membrane potential and discharge rate of suprachiasmatic neurons. Brain Res 603:284-288.

Mintz EM, Marvel CL, Gillespie CF, Price KM, Albers HE (1999) Activation of NMDA receptors in the suprachiasmatic nucleus pro- 
duces light-like phase shifts on the circadian clock in vivo. J Neurosci 19:5124-5130.

Pickard GE, Rea MA (1998) Serotonergic innervation of the hypothalamic suprachiasmatic nucleus and photic regulation of circadian rhythms. Biol Cell 89:513-523.

Pratt BL, Goldman BD (1986) Activity rhythms and photoperiodism of Syrian hamsters in a simulated burrow system. Physiol Behav 36:83-89.

Prosser RA (1998) Neuropeptide Y blocks serotonergic phase shifts of the suprachiasmatic circadian clock in vitro. Brain Res 808:31-41.

Quintero JE, McMahon DG (1999) Serotonin modulates glutamate responses in isolated suprachiasmatic nucleus neurons. J Neurophysiol 82:533-539.

Ralph MR, Mrosovsky N (1992) Behavioral inhibition of circadian responses to light. J Biol Rhythms 7:353-359.

Rea MA, Glass JD, Colwell CS (1994) Serotonin modulates photic responses in the hamster suprachiasmatic nuclei. J Neurosci 14:3635-3642.

Ribelayga C, Pevet P, Simonneaux V (1998) Possible involvement of neuropeptide $\mathrm{Y}$ in the seasonal control of hydroxyindole- $O$ methyltransferase activity in the pineal gland of the European hamster (Cricetus cricetus). Brain Res 801:137-142.

Rudolf K, Eberlein W, Engel W, Wieland HA, Willim KD, Entzeroth M, Wienen W, Beck-Sickinger AG, Doods HN (1994) The first highly potent and selective non-peptide neuropeptide Y Y1receptor antagonist: BIBP3226. Eur J Pharmacol 271:R11-R13.

Shibata S, Watanabe A, Hamada T, Ono M, Watanabe S (1994) $N$-Methyl-D-aspartate induces phase shifts in circadian rhythm of neuronal activity of rat SCN in vitro. Am J Physiol 267:R360-R364.

Shirakawa T, Moore RY (1994) Glutamate shifts the phase of the circadian neuronal firing rhythm in the rat suprachiasmatic nucleus in vitro. Neurosci Lett 178:47-50.
Tischkau SA, Gallman EA, Buchanan GF, Gillette MU (2000) Differential cAMP gating of glutamatergic signaling regulates long-term changes in the suprachiasmatic circadian clock. J Neurosci 20:7830-7837.

van den Pol AN, Obrietan K, Cao V, Trombley PQ (1996) Neuropeptide Y-mediated long term depression of exitatory activity in suprachiasmatic nucleus neurons. J Neurosci 16:5883-5895.

Weber ET, Rea MA (1997) Neuropeptide Y blocks light-induced phase advances but not delays of the circadian activity rhythm in hamsters. Neurosci Lett 231:159-162.

Weber ET, Gannon RL, Rea MA (1998) Local administration of serotonin agonists blocks light-induced phase advances of the circadian activity rhythm in the hamster. J Biol Rhythms 13:209-218.

Weinberg DH, Sirinathsinghji DJ, Tan CP, Shiao LL, Morin N, Rigby MR, Heavens RH, Rapoport DR, Bayne ML, Cascieri MA, Strader CD, Linemeyer DL, MacNeil DJ (1996) Cloning and expression of a novel neuropeptide Y receptor. J Biol Chem 271:16435-16438.

Wieland HA, Willim KD, Entzeroth M, Wienen W, Rudolf K, Eberlein W, Engel W, Doods HN (1995) Subtype selectivity and antagonistic profile of the nonpeptide Y1 receptor antagonist BIBP 3226. J Pharmacol Exp Ther 275:143-149.

Yannielli PC, Harrington ME (2000) Neuropeptide Y applied in vitro can block the phase shifts induced by light in vivo. NeuroReport 11:1587-1591.

Youngman MA, McNally JJ, Lovenberg TW, Reitz AB, Willard NM, Nepomuceno DH, Wilson SJ, Crooke JJ, Rosenthal D, Vaidya AH, Dax SL (2000) $\alpha$-Substituted $N$-(sulfonamido)alkyl- $\beta$-aminotetralins: potent and selective neuropeptide Y Y5 receptor antagonists. J Med Chem 43:346-350. 